\title{
Biosurfactant production by Trichoderma sp. MK116452 and its possible application in oil recovery
}

Nur Bazilah Afifah Matussin

Environmental and Life Sciences, Faculty of Science

Pooja Shivanand ( $\nabla$ pooja.shivanand@ubd.edu.bn )

Universiti Brunei Darussalam https://orcid.org/0000-0002-5740-6234

Lee Hoon Lim

Chemical Sciences, Faculty of Science

\section{Research}

Keywords: Biosurfactant, Trichoderma sp., MEOR, Crude oil

Posted Date: July 1st, 2020

DOI: https://doi.org/10.21203/rs.3.rs-19741/v2

License: (c) (i) This work is licensed under a Creative Commons Attribution 4.0 International License.

Read Full License 


\title{
Biosurfactant production by Trichoderma sp. MK116452 and its possible application in oil recovery
}

Nur Bazilah Afifah Matussin ${ }^{\mathrm{a}}$, Pooja Shivanand ${ }^{\mathrm{a}^{*}}$, Lee Hoon Lim ${ }^{\mathrm{b}}$

${ }^{a}$ Environmental and Life Sciences, Faculty of Science, Universiti Brunei Darussalam, Jalan

Tungku Link, Gadong BE1410, Negara Brunei Darussalam

${ }^{\mathrm{b}}$ Chemical Sciences, Faculty of Science, Universiti Brunei Darussalam, Jalan Tungku Link, Gadong BE1410, Negara Brunei Darussalam

*Corresponding author

Email: pooja.shivanand@ubd.edu.bn; poojashivanand@outlook.com; Tel: +673 2460923 ext 1378

ORCID ID: 0000-0002-5740-6234

\begin{abstract}
Surfactants are amphiphatic compounds containing both hydrophilic and hydrophobic groups, which are capable of lowering surface or interfacial tension. Considering the advantages of using biosurfactants produced by microorganisms, the aim of this study was to develop and characterise a biosurfactant produced by Trichoderma sp. MK116452 isolated from Seri Chermin filling station, Brunei Darussalam, and to examine its potential application in microbial enhanced oil recovery (MEOR). The microorganism was cultured in a minimal salt medium containing $1 \%$ crude oil as a carbon source and a cell-free culture broth was used to screen its efficiency in producing biosurfactants. Characterisation of the biosurfactant showed the presence of glycosides and fatty acids, suggesting its glycolipidic nature. The isolated biosurfactant showed no toxicity to the micro-crustacean Artemia salina or to red bean (Vigna angularis). The extracted biosurfactant was effective at recovering up to $60 \%$ of crude oil from sand using the sand pack column method, which is similar to the recovery rate for a chemical surfactant (SDS) (65\%). These findings highlight the potential use of Trichoderma sp. MK116452 biosurfactant in the oil industry.
\end{abstract}

Keywords: Biosurfactant; Trichoderma sp.; MEOR; Crude oil 


\section{Introduction}

Rapid urbanization and industrialization are the results of increase in global consumption of crude oil. Naturally, only $30-40 \%$ of oil that could be retrieved by conventional recovery techniques whereas the remaining 60-70\% of oil are still trapped in the reservoirs. (Qazi et al. 2013; Ashish and Debnath (Das) 2018). Due to the fluctuation of oil prices in recent years have cause imbalances in market supply and demand, though the prices are estimated to maintain within $\$ 30-60 / \mathrm{bbl}$ for long period of time. Therefore, countries and petroleum industries that are highly reliant on oilbased income are needed to come with upgraded technologies for more economical and effective outcomes.(Geetha et al. 2018; Câmara et al. 2019). These technologies were developed to improve oil extraction and recovery yields including enhanced oil recovery (EOR).

Low permeability of rocks in the reservoirs and high viscosity of crude oil play roles in inhibiting oil recovery by conventional methods. Hence, the use of chemicals to enhance oil recovery are applied to increase oil production by altering the interfacial tension, fluid properties, and the permeability of oil zones (Qazi et al. 2013; de Araujo et al. 2019). However, chemicals can be expensive and harmful to environment. Other alternative such as microbial enhanced oil recovery has obtained attention because of its environmentally friendly nature, applicability, and cost effectiveness (Ali et al. 2019).

MEOR is the involvement of microorganisms or their metabolic products in a biological process to amend reservoir conditions and discharge trapped oil. Biosurfactant-mediated MEOR is the use of biosurfactant produced by specific microorganisms to enhance oil recovery (Luna et al. 2016; Kanna 2017; de Araujo et al. 2019). Biosurfactants have several advantages over chemical surfactants such as low critical micelle concentration, high biodegradability, greater stability under extreme conditions, and low toxicity which make them a better choice for oil recovery (Ashish and Debnath (Das) 2018; Astuti et al. 2019; Maia et al. 2019). In oil recovery, biosurfactant indorse the formation of micelles and lower the interfacial tension between oil and water, which gives a physical mechanism for mobilizing oil with a moving aqueous phase, thereby the trapped residual oil from reservoirs are released (Kanna 2017; Maia et al. 2019). 
In this study, Trichoderma sp. MK116452 was used to produce a biosurfactant, which was assessed for its characterisation, toxicity, and potential for enhanced oil recovery using the sand pack column method.

\section{Materials and methods}

The fungal isolate Trichoderma sp. (NCBI GenBank: MK116452), previously isolated from Seri Chermin filling station, Brunei Darussalam $\left(4^{\circ} 55^{\prime} 59.4^{\prime \prime} \mathrm{N}, 115^{\circ} 01^{\prime} 06.1^{\prime \prime} \mathrm{E}\right)$ was used in this study. This strain was maintained in Sabouraud dextrose agar for repetitive usage. Sabouraud dextrose broth was used to activate the fungus, which was incubated at $30{ }^{\circ} \mathrm{C}$ for seven days and shaken at $120 \mathrm{rpm}$ (Shaker 10-500 rpm, Incubating Bench top, capacity $53 \mathrm{~L}$, lab companion ${ }^{\mathrm{TM}}$ ). This inoculum was used to produce a biosurfactant in minimal salt medium (MSM). The MSM contained sucrose $40 \mathrm{~g} / \mathrm{L}$; yeast extract $18.8 \mathrm{~g} / \mathrm{L}$; sodium acetate $0.5 \mathrm{~g} / \mathrm{L}$; sodium benzoate $0.1 \mathrm{~g} / \mathrm{L}$; $\mathrm{MgSO}_{4} .7 \mathrm{H}_{2} \mathrm{O} 0.5 \mathrm{~g} / \mathrm{L} ;\left(\mathrm{NH}_{4}\right)_{2} \mathrm{SO}_{4} 3 \mathrm{~g} / \mathrm{L} ; \mathrm{KH}_{2} \mathrm{PO}_{4} 2 \mathrm{~g} / \mathrm{L} ; \mathrm{NaCl} 0.9 \mathrm{~g} / \mathrm{L} ;$ and $2 \%$ crude oil was used as an additional carbon source. First, $1 \%$ of $48-72 \mathrm{~h}$ seed culture of the fungal strain was inoculated into the production medium (MSM). The cultivation was achieved in a $500 \mathrm{~mL}$ Erlenmeyer flask at $30{ }^{\circ} \mathrm{C}$ and $120 \mathrm{rpm}$ for seven days in an incubator shaker. The production medium was centrifuged at $10,000 \mathrm{rpm}$ at $4{ }^{\circ} \mathrm{C}$ for $20 \mathrm{~min}$ and filtered through Whatman filter paper No. 1 under vacuum conditions where the cell free supernatant was accumulated and analysed for biosurfactant production.

\subsection{Biosurfactant screening}

For screening of biosurfactants, three different tests were performed, following the protocol of (Morikawa et al. 1993; Bodour and Miller-Maier 1998; Walter et al. 2010; Parthipan et al. 2017a).

\subsubsection{Drop-collapse assay}

In a drop-collapse assay, $2 \mu \mathrm{L}$ of crude oil was injected into 12 well plates and $5 \mu \mathrm{L}$ of cell-free culture broth was added onto the surface of the oil. The drop size was observed after 1 min with the aid of a magnifying glass. A negative control was maintained using distilled water (without surfactant) and the chemical surfactant sodium dodecyl sulphate (SDS) was used as a positive control. Positive results for biosurfactant production resulted in a drop diameter that was at least 1 $\mathrm{mm}$ larger than that produced by distilled water. 


\subsubsection{Oil displacement assay}

An empty petri dish was filled with $50 \mathrm{~mL}$ of distilled water and $100 \mu \mathrm{L}$ of crude oil was added on the water surface. Then, on the crude oil surface, $10 \mu \mathrm{L}$ of culture filtrate was dropped and with the present of surfactant, the crude oil was displaced and gave a diameter of clear zone. Furthermore, distilled water was used as negative control where no displacement and clear zone was observed whereas SDS was used as positive control.

\subsubsection{Emulsification activity}

For this assay, $3 \mathrm{~mL}$ of crude oil was dispensed into a test tube which comprised of $3 \mathrm{~mL}$ biosurfactant solution. The test tube was maintained for $24 \mathrm{~h}$ after being vigorously vortexed for 2 min and the emulsion height, oil and aqueous zones were measured. The emulsion index (E24) was determined as the percentage of height of the emulsified layer $(\mathrm{mm})$ divided by the total height of the liquid column (mm).

\subsection{Biosurfactant extraction}

For extraction of the biosurfactant, the cell-free supernatant served as the source of the crude biosurfactant and this supernatant was acidified to $\mathrm{pH} 2$ using $6 \mathrm{~N} \mathrm{HCl}$ and left overnight at $4{ }^{\circ} \mathrm{C}$ for precipitation. The precipitated biosurfactant was pooled by centrifugation (Sigma 13k) at $10,000 \mathrm{rpm}$ at $4{ }^{\circ} \mathrm{C}$ for $20 \mathrm{~min}$ and the precipitate was suspended in double-deionised water and $\mathrm{pH}$ was adjusted to $\mathrm{pH} 7$. The biosurfactant solution was then extracted three times using chloroform:methanol (2:1) for further purification, where only the organic phase was collected. The organic phase was dried in the oven at $40{ }^{\circ} \mathrm{C}$ for a few days until the weight of the product stabilised. The surfactant assembled after the extraction was believed to be a partially purified biosurfactant and was applied for characterisation purposes.

\subsection{Dry biomass estimation}

Dry biomass was obtained by centrifugation at 10,000 rpm and the supernatant was removed and the pellet was retained. To acquire a complete separated fungal biomass, the centrifugation was made twice under the same conditions. The pellet was then washed with distilled water and weighed on filter paper after drying at $80{ }^{\circ} \mathrm{C}$ for an hour. 


\subsection{Characterization of the biosurfactant}

\subsubsection{Thin layer chromatography (TLC)}

For thin layer chromatography (TLC), $0.1 \mathrm{~g}$ of partially purified biosurfactant was dissolved in 1 $\mathrm{mL}$ of water for analysis, with a chloroform:methanol:water ratio of 65:25:4 (v/v/v) solution as the developing solvent (Zhang et al. 2012).

\subsubsection{Glycolipids}

The TLC plate was spurted with phenol-sulphuric acid reagent and desiccated at $100-110{ }^{\circ} \mathrm{C}$ for 10-15 min. The phenol sulphuric acid reagent contained $3 \mathrm{~g}$ of phenol and $5 \mathrm{~mL}$ of sulphuric acid in $95 \mathrm{~mL}$ of ethanol. Brown dots were observed on the TLC plate indicate the presence of glycolipids.

\subsubsection{Lipids}

The plate was placed vertically in a chamber saturated with iodine vapour. Iodine binds to the unsaturated carbon bonds of lipid molecules, resulting in dark bands along the TLC plates.

\subsubsection{Proteins}

The TLC plate was sprayed using ninhydrin solution $(0.2 \mathrm{~g}$ of ninhydrin dissolved in $12 \mathrm{~mL}$ of $95 \%$ ethanol). After spraying, it was dried at $100-100{ }^{\circ} \mathrm{C}$ for $10-15 \mathrm{~min}$ and the presence of protein was recorded based on the appearance of colour on the TLC plate.

\subsubsection{Fourier-transform infrared spectrum (FTIR)}

To examine the functionalities associated with biosurfactant, FTIR (Alpha T Bruker) was used. The purified biosurfactant was dried in an oven at $120{ }^{\circ} \mathrm{C}$ for $2 \mathrm{~h}$ before it was ground with potassium bromide $(\mathrm{KBr})$ at a ratio of 1:100 (0.002 $\mathrm{g}$ of partially purified biosurfactant was ground with $0.2 \mathrm{~g}$ of $\mathrm{KBr}$ ). The pellet was secured in the sample container and analysed in IR region (400$4500 \mathrm{~cm}^{-1}$ ) at room temperature.

\subsubsection{Gas chromatography- mass spectrometry}

The gas chromatography mass spectrum was done by Professor Steven Yuan from National University of Singapore. The column used was Agilent 12623, RTX-5ms (30 m x $250 \mu \mathrm{m}$ x 0.25 $\mu \mathrm{m})$ where first $10 \mathrm{mg}$ of biosurfactant was dissolved in methanol and $5 \mu \mathrm{l}$ of the sample was injected into a gas chromatograph under splitless condition. The carrier gas used was helium with the flow rate of $1.5 \mathrm{~mL} / \mathrm{min}$ and the working temperature of the $\mathrm{GC}$ injector was $260{ }^{\circ} \mathrm{C}$. The 
gradient temperature was set at a speed of $5{ }^{\circ} \mathrm{C}$ per minute ranging from 60 to $260{ }^{\circ} \mathrm{C}$ and maintained at $260{ }^{\circ} \mathrm{C}$ for 10 minutes at the end of analysis. The mass spectra were obtained with a mass range of 30-500 amu. The identification of components was done in scan mode by using NISTII and the target mass spectra obtained from samples were compared with mass spectra obtained from the library.

\subsubsection{SEM-EDS}

Morphological studies of the biosurfactant were performed using field emission scanning electron microscopy (FESEM, JSEM-7610F). The samples were dried and coated with carbon prior to the measurement. The image was taken at 10,000x in high resolution and the elemental measurement was carried out using EDS.

\subsection{Toxicity test of biosurfactant}

\subsubsection{Cytotoxicity test}

The cytotoxic effects of the biosurfactant were tested using a brine shrimp assay (Solis et al. 2006; Qazi et al. 2013; High et al. 2016). Several concentrations of partially purified biosurfactant (100, 1000 , and 10,000 ppm) were dissolved in water. For preparation of artificial sea water, $34 \mathrm{~g}$ of commercial sea salt was dissolved in $1 \mathrm{~L}$ of distilled water. Four litres of the salt water were poured into a shallow rectangular dish and this dish was divided into two unequal compartments by fitting Styrofoam with several $5 \mathrm{~mm}$ holes as a divider. Three grams of brine shrimp eggs (Artemia salina) was soaked in Chlorox ${ }^{\circledR}$ for 5 mins and then ground using filter paper. These eggs were sprinkled onto a large portion of the dish. Aluminium foil was used to cover the larger portion of the dish to provide darkness for the eggs to hatch, while the smaller portion was kept in light; the temperature of the salt water was maintained at $30{ }^{\circ} \mathrm{C}$. Brine shrimp began to hatch within $24 \mathrm{~h}$ and were left for another $6 \mathrm{~h}$ to mature. The nauplii (brine shrimp larvae) were collected using a Pasteur pipette. For the assay, 12 well plates were filled with $2 \mathrm{~mL}$ of salt water and ten shrimps were transferred to the well plate by pipette and the volume of sea water was maximized to $5 \mathrm{~mL}$. The 12 well plates were placed under light at $25-30{ }^{\circ} \mathrm{C}$. The number of surviving and dead shrimp were counted with the aid of a magnifying glass after $24 \mathrm{~h}$. The toxicity was measured by the LC50 dose, where LC50 > 1000 indicates no toxicity of the surfactant for brine shrimp. 


\subsubsection{Phytotoxicity test}

Phytotoxic effects of different concentrations of partially purified biosurfactant $(10,30$, and 60 $\mathrm{mg} / \mathrm{mL}$ ) were analysed using red bean (Vigna angularis) (Sobrinho et al. 2013; Rufino et al. 2014; Sharma et al. 2014). Seed surfaces were sterilized using 5\% sodium hypochlorite for $30 \mathrm{~min}$ and rinsed with sterile distilled water. Sterile filter paper in the glass petri dish was wetted with $5 \mathrm{~mL}$ of the samples before adding a total of 20 seeds into the petri dish. The seeds were incubated at 25 ${ }^{\circ} \mathrm{C}$ for three days under light and the mean number of germinated seeds was counted on day 3 . For the negative control, distilled water was used, whereas SDS was used as a positive control. Experiments were performed in triplicate. The percentage seed germination was calculated as

$$
A-B=\frac{C}{\text { Total no of seeds }} \times 100
$$

where A is the total number of seeds germinated in the negative control (distilled water) and B is the total number of seeds germinated in the sample.

\subsection{Sand pack column method for oil recovery}

For oil recovery, the methods described by (Ashish and Debnath (Das) 2018; Sharma et al. 2018; Ghazala et al. 2019; Maia et al. 2019) were used with slight modifications. The biosurfactant was analysed using artificially contaminated sand, where $50 \mathrm{~g}$ of sand was mixed with $15 \mathrm{~mL}$ crude oil in a $100 \mathrm{~mL}$ Erlenmeyer flask and was shaken for $24 \mathrm{~h}$. The sand was put in the column and washed with $5 \%$ brine water until no additional oil was discharged in the effluent, indicating that the crude oil was trapped in the sand. The amount of oil washed off was measured. Next, $2 \mathrm{~mL}$ of biosurfactant solution $(1 \mathrm{~g} / \mathrm{L})$ was added to the column and incubated at room temperature for 24 h. After incubation, the sand was washed using 5\% brine water and the oil discharged was measured until no additional oil washed off. The percentage of oil recovery was calculated as

Percentage of oil recovery $(\%)=\frac{\text { Amount of oil washed off after adding surfactant }(\mathrm{mL})}{\text { Amount of oil added to the sand }- \text { Amount of oil wasehd off by brine solution }}$ 


\section{Results}

\subsection{Biosurfactant screening}

At the end of frequent sub-culturing and screening methods, Trichoderma sp. MK116452 was recognised as an outstanding biosurfactant producer. The strain applied in this experiment gave positive results for all biosurfactant screening methods. In the drop-collapse assay, drop collapse was up to $3.67 \pm 0.29 \mathrm{~mm}$ (the value for distilled water is $2 \pm 0 \mathrm{~mm}$ ), indicating a high amount of biosurfactant present in the solution. The emulsification index was $17.82 \pm 1.34 \%$ for initial screening. These results indicate that the biosurfactant produced by Trichoderma sp. MK116452 possesses low emulsifying activity. In the oil displacement assay, addition of the surfactant solution to the crude oil layer gave a clear zone of $7.3 \pm 0.2 \mathrm{~cm}$. This result proved the presence of biosurfactant in the cell-free culture broth.

\subsection{Biosurfactant yield}

To determine the production of biosurfactant using different fungal strains, all factors were kept constant: $\mathrm{pH}$ 5.6, incubation temperature of $30^{\circ} \mathrm{C}$ for $7 \mathrm{~d}, 1 \%$ of two-day-old inoculum, crude oil as the carbon source, and using the same media (MSM). Trichoderma sp. MK116452 produced a biosurfactant yield of $6.33 \pm 1.70 \mathrm{~g} / \mathrm{L}$ after purification with chloroform and methanol with a biomass of $1.08 \pm 0.005 \mathrm{~g}$.

\subsection{Characterization of biosurfactant}

\subsubsection{Thin layer chromatography (TLC)}

Different tests were applied to determine the presence of proteins, sugars, and fatty acids in the crude extracts of Trichoderma sp. MK116452. The ninhydrin reaction showed no changes in colour, therefore, no compounds representing proteins were present in the biosurfactant produced by Trichoderma sp. MK116452. The sulphuric acid-phenol reaction appeared saffron yellow, indicating the presence of sugar. This suggests that glycolipids were produced by Trichoderma sp. MK116452. Iodine vapour was used to check for the presence of lipids and the surfactants produced by Trichoderma sp. MK116452 showed dark bands along the TLC plate. 


\subsubsection{Fourier-transform infrared (FTIR) spectrum}

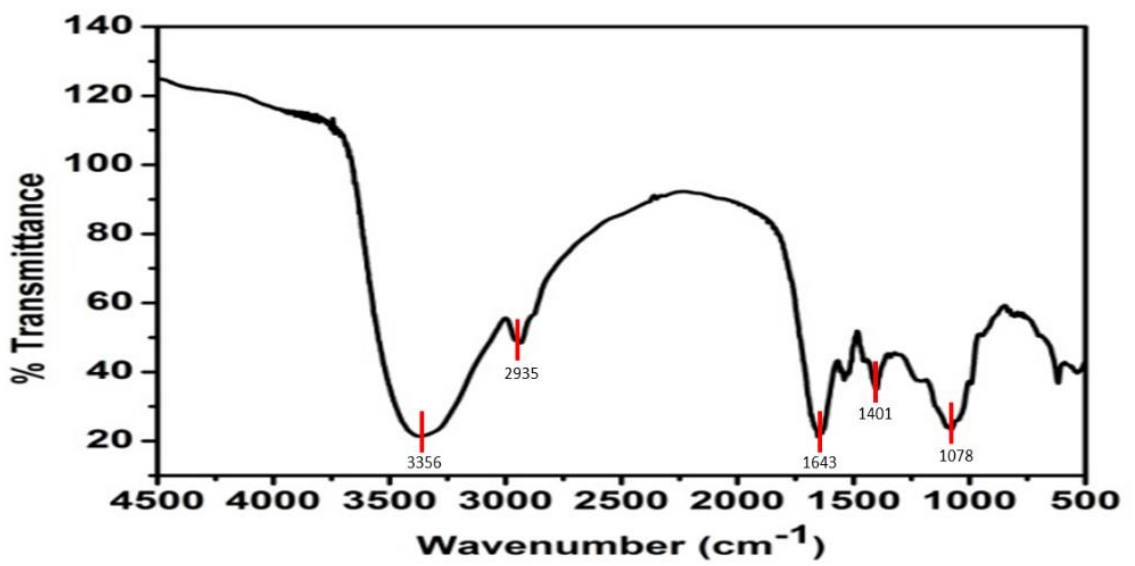

Figure 1 Fourier-transform infrared (FTIR) spectrum for a biosurfactant from Trichoderma sp. MK116452

The FTIR spectrum of the purified biosurfactant powder showed a peak at $3550-3200 \mathrm{~cm}^{-1}$ indicating the presence of $\mathrm{O}-\mathrm{H}$ bonds. The peak at $1648-1638 \mathrm{~cm}^{-1}$ indicates the existence of alkenes $(C=C)$ and the strong peak at $1408-1400 \mathrm{~cm}^{-1}$ was likely due to the presence of sulphur $(\mathrm{S}=\mathrm{O})$. The absorption band at $2960-2930 \mathrm{~cm}^{-1}$ verified the amount of $\mathrm{C}-\mathrm{H}$ stretching vibrations of hydrocarbon chains of alkyl $\left(\mathrm{CH}_{2}-\mathrm{CH}_{3}\right)$ groups. FTIR spectrum showed the occurrence of glycosidic bonds (C-O-C) in the molecules at the absorption band of 1098-1052 $\mathrm{cm}^{-1}$. In summary, the biosurfactant produced by Trichoderma sp. belongs to the glycolipid group.

\subsubsection{Gas chromatography-mass spectrometry}

Biosurfactant extracted from Trichoderma sp. MK116452 further revealed the existence of glycolipid after it was run on gas chromatography-mass spectrometry as the majority of fatty acid chains in the surfactant was hexadecanoic acid. The surfactant consists of six compounds including benzaldehyde, 4-methyl; 2,4 di-tert-butyl phenol, methyl ester; hexadecenoic acid, methyl ester; 9-hexadecenoic acid, methyl ester; hexadecenoic acid, methyl ester; 9-octadecenoic acid, methyl ester and, heptadecanoic acid, 16-methyl, methyl ester as shown in Table 1. 
Table 1 GC-MS result for surfactant from Trichoderma sp. MK116452

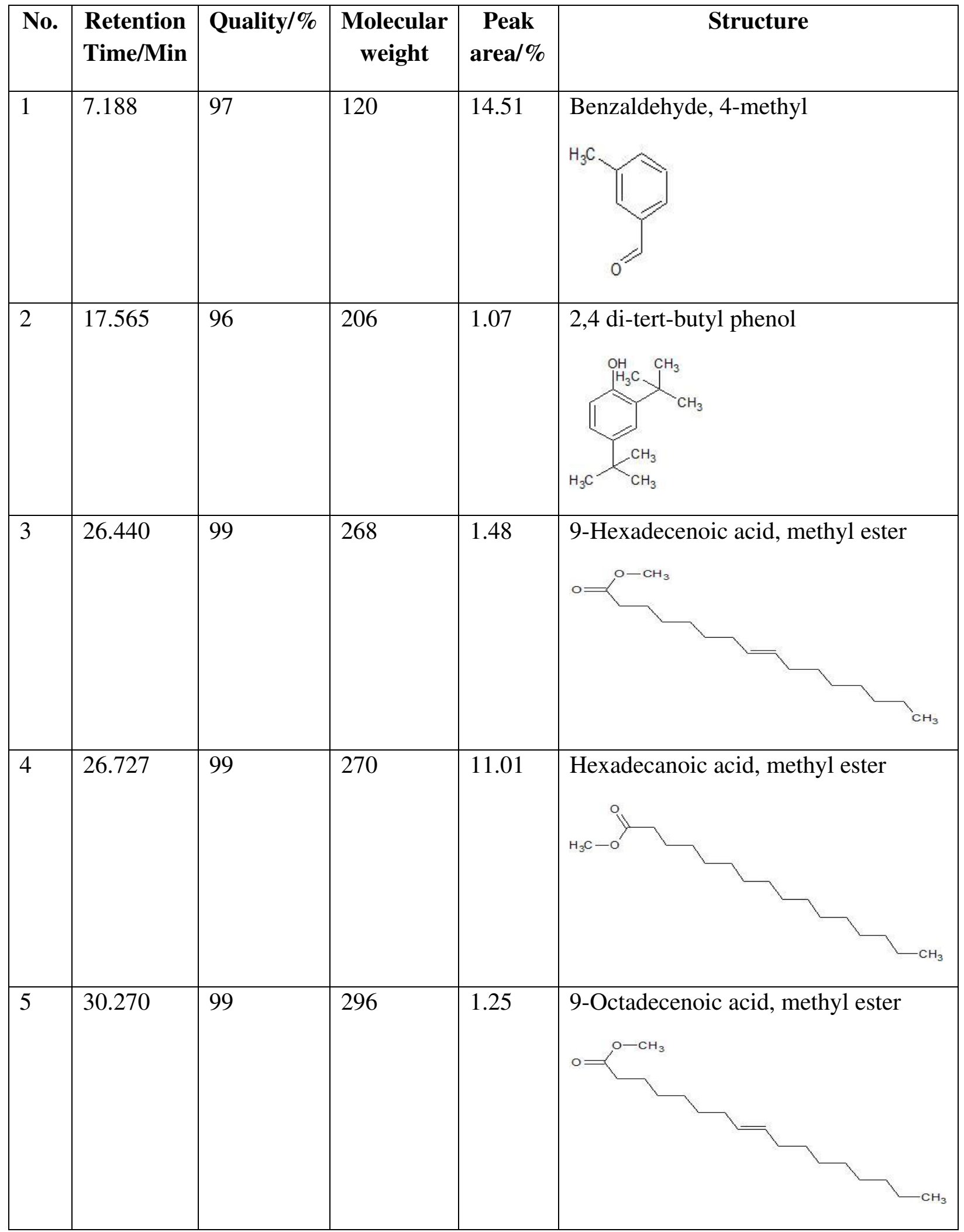




\begin{tabular}{|l|l|l|l|l|l|}
\hline 6 & 30.762 & 95 & 298 & 3.57 & $\begin{array}{l}\text { Heptadecanoic acid, 16-methyl, } \\
\text { methyl ester }\end{array}$
\end{tabular}

\subsubsection{SEM-EDS}

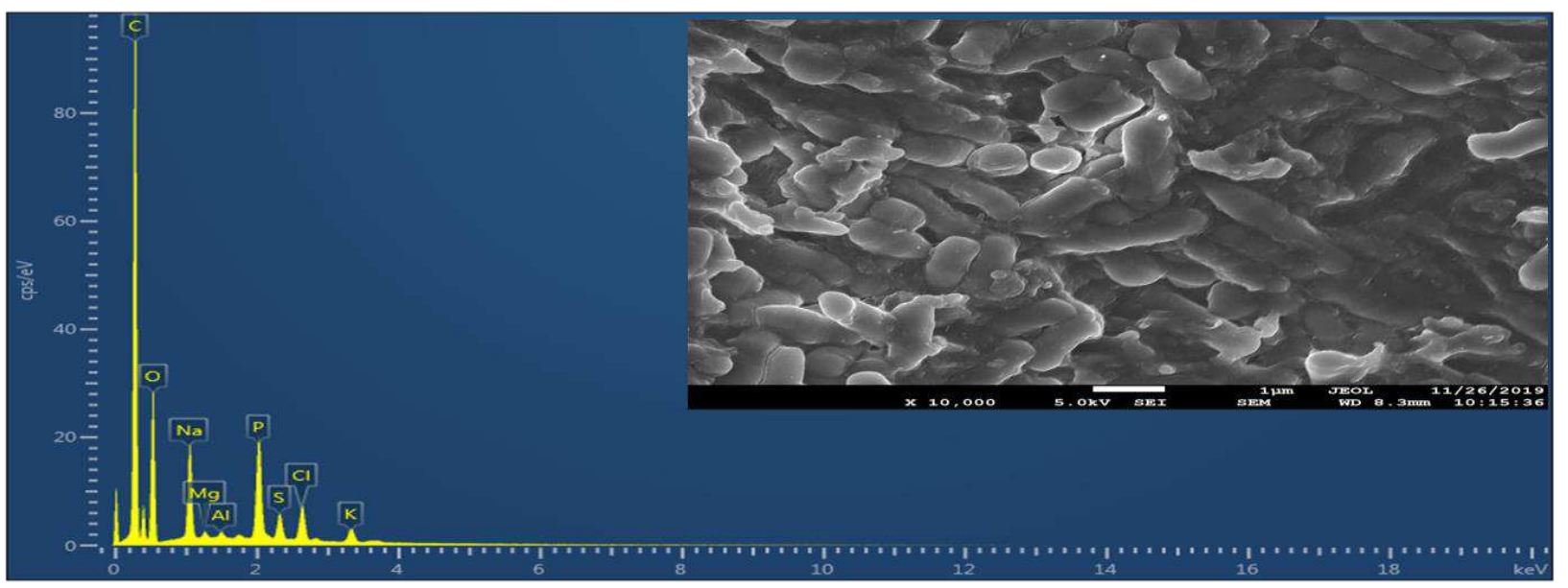

Figure 2 SEM EDS images for biosurfactant produced by Trichoderma sp. MK116452

SEM-EDS is when electron microscope in fact be equipped with an energy dispersive X-ray detector and this device can provide the accurate chemical composition of the sample being analyzed. From Figure 2, the purified biosurfactant in the SEM-EDS analysis showed the presence of oxygen, sodium, phosphorus, chlorine and potassium in a ratio of 62.20, 14.33, 11.60, 4.70 and 2.21 for surfactant produced by Trichoderma sp. MK116452.

\subsection{Toxicity test}

\subsubsection{Cytotoxicity test}

LC50 values were used to determine the toxicity of the surfactant where, according to Mayer's toxicity index, $\mathrm{LC}_{50} 1000 \mu \mathrm{g} / \mathrm{mL}$ was categorised as toxic, while extracts with LC50 values $>1000$ were considered non-toxic (Santos et al. 2017). The biosurfactant from Trichoderma sp. MK116452 resulted in LC50 values > 1000, indicating low toxicity. 
Table 2 Cytotoxicity test of surfactant from Trichoderma sp. MK116452

\begin{tabular}{|l|l|l|}
\hline & $\begin{array}{l}\text { Percentage of } \\
\text { brine shrimp } \\
\text { alive/\% }\end{array}$ & LC50 \\
\hline $100 \mathrm{ppm}$ & 100 & \multirow{2}{*}{$>1000$} \\
\hline $1000 \mathrm{ppm}$ & 100 & \\
\hline $10,000 \mathrm{ppm}$ & $93.33 \pm 5.78$ & \\
\hline
\end{tabular}

\subsubsection{Phytotoxicity test}

The germination index (GI) was employed to assess the toxicity of biosurfactant to plant by combining measures of relative seed germination and relative root elongation. GI values $<80 \%$ were used as an indicator of phytotoxicity (Rufino et al. 2014). The results showed that there were no inhibitory effects observed on seed germination or root elongation of red bean by the solutions tested, and GI values $>80 \%$ were found for biosurfactant solutions of 10,30 , and $60 \mathrm{mg} / \mathrm{mL}$. SDS was also tested for phytotoxicity and GI values were $<6 \%$ for 10,30 , and $60 \mathrm{mg} / \mathrm{mL}$ concentrations, indicating that SDS was highly toxic to the plant.

Table 3 Phytotoxicity test of surfactant from Trichoderma sp. MK116452

\begin{tabular}{|l|l|l|l|}
\hline & $\begin{array}{l}\text { Percentage } \\
\text { germination }(\%)\end{array}$ & $\begin{array}{l}\text { Mean length of roots } \\
(\mathrm{mm})\end{array}$ & $\begin{array}{l}\text { Germination index } \\
(\%)\end{array}$ \\
\hline $10 \mathrm{mg} / \mathrm{mL}$ & $106.25 \pm 0.58$ & $17.33 \pm 5.86$ & 204.63 \\
\hline $30 \mathrm{mg} / \mathrm{mL}$ & $87.5 \pm 0.58$ & $9 \pm 1$ & 100 \\
\hline $60 \mathrm{mg} / \mathrm{mL}$ & $87.5 \pm 0.58$ & $8.33 \pm 0.58$ & 81.02 \\
\hline
\end{tabular}

\subsection{Sand pack column for oil recovery}

To study the efficacy and applicability of crude biosurfacant extracted from the cell free culture broth of Trichoderma sp. MK116462 for enhanced oil recovery, the biosurfactant solution was inserted into the column at room temperature. The total oil recovered using the surfactant was $63.33 \pm 5.77 \%$, which is slightly lower than that of the positive control (SDS: 65\%), whereas water could only recover $16 \%$ of the oil. This result shows that the surfactant from Trichoderma sp. MK116452 can help to enhance oil recovery. 


\section{Discussion}

Many studies have demonstrated the efficiency of fungi in biosurfactant production and these biosurfactants were employed in many applications such as oil degradation and recovery to improve their success rate. For screening, drop-collapse assay is one of the easiest methods for detection of biosurfactants as it can detect the presence of surfactants even at low concentrations (Dhiman et al. 2016; Ndlovu and Rautenbach 2017). Moreover, the diameter of the sample drop also increases as the surfactant concentration increases (Varjani and Upasani 2017). The oil spreading method is another effective technique to detect the presence of biosurfactants. In this method, if the biosurfactant is present in the supernatant, the oil is displaced and a clearing zone is formed (Liu et al. 2013). The diameter of this clearing zone on the oil surface correlates with surfactant activity, also called oil displacement activity. For pure biosurfactants, there is a linear association between the quantity of surfactant and clearing zone diameter (Walter et al. 2010); the larger the diameter of the clear zone, the higher the surface activity of the test solution (Zhang et al. 2012). The oil spreading area or clear zone in this assay was directly proportional to the concentration of the biosurfactant in the solution (Parthipan et al. 2017b). Trichoderma can produce large amounts of biosurfactant in a short period of time. Maheswari and Parveen (2012) reported that Trichoderma viride produced a diameter of $47 \mathrm{~mm}$ in an oil spreading assay and was capable of degrading toluene (Maheswari and Parveen 2012).

Emulsification assay is an indirect method to screen biosurfactant production (Thavasi et al. 2013). This assay determines the productivity of bioemulsifiers. Emulsifier production is induced by the growth of surfactants on hydrocarbons, thus, microorganisms that do not produce the emulsifier, do not produce biosurfactants (Ron and Rosenberg 2002; Satpute et al. 2010). However, surface activity and emulsification capacity do not always correlate, as shown in our results (Raza et al. 2007).

Maximum biosurfactant production by Trichoderma viride was recorded at a mass of $1.2 \pm 0.86 \mathrm{~g}$ in $100 \mathrm{~mL}$ of media with diesel as a carbon source, when compared with production for other oils such as kerosene, petrol, and vegetable oil (Maheswari and Parveen 2012). However, there are no records of biosurfactants produced by Trichoderma sp. using crude oil as a carbon source that could support the findings in this research. Carbon is one of the factors that could affect the production of surfactants. 
Trichoderma sp. MK116452 was suspected to produce a glycolipid biosurfactant, as sugars and lipids were observed in the TLC results. No previous studies have examined the structure and functional groups of the biosurfactant produced by Trichoderma. FTIR analysis in Figure 1 showed the existence of seven peaks. These absorption peaks demonstrated the presence of fatty acids, sulphonates, and glycosides (Patowary et al. 2017). From mass spectrometry, the discovered compounds were mostly fatty acids in nature such as hexadecanoic acid and octadecenoic acid (Bhawsar and Singh, 2016; Ibrahim et al., 2013; Parthipan et al., 2017). In various studies of glycolipid, hexadecanoic acid was found as the main fatty acid chains similarly with the finding in this research and it confirmed that the surfactant produced by Trichoderma sp. MK116452 was glycolipid (Sharma et al. 2014, 2015; Santhappan and Pandian 2017). In glycolipid produced by Pseudomonas and Rhodococcus species predominantly consist of 3, hydroxy fatty acid but could not be found in the surfactant from Trichoderma species in this study and this could be due to different substrates influence the structural formation of surfactant (Peng et al. 2008; CortésSánchez et al. 2013). There was no distinct group of glycolipids illustrated in the mass spectrum, therefore further analysis such as NMR needed to further identify the structure of surfactant produced by Trichoderma species. SEM imaging in Figure 2 showed the structural porous web of biosurfactant similarly with the research that has been done by Bansal et al., 2019, where glycolipid was observed under SEM (Bansal et al. 2019). The presence of oxygen in a relatively abundant quantity designates the existence of carbohydrate and lipid complex moiety in the biosurfactant samples (Patowary et al. 2017). The size of biosurfactant produced by Trichoderma sp. MK116452 was $3 \mathrm{~nm}$ with a total of 10,634 particles. The size of surfactant is important as smaller size of the particles could improve adsorption ratio and rate of reaction which make them more favorable to be used for enhancement of oil recovery (Geetha et al. 2018).

Due to environmental concerns, in this study the biosurfactant product was examined for cytotoxic and phytotoxic potential. The results showed that the biosurfactant would not be cytotoxic to indigenous microflora and it was found to be safe for environmental applications. However, the biosurfactant did show phytotoxic effects when applied at high concentrations as the GI decreased at a high concentration of surfactant applied to the beans. The inhibition of seed germination in lettuce gradually increased when surfactant from Candida lipolytica was applied (Rufino et al. 2014; Santos et al. 2017). This finding indicates that this product could be used in agriculture as a bio-pesticide to control weeds (Qazi et al. 2013). 
There were numerous articles emphasizing the achievement of ex situ biosurfactant-mediated MEOR at the laboratory scale, which highlights the comfort of application and huge success rate (Qazi et al. 2013; Kanna 2017; Ashish and Debnath (Das) 2018; Santos et al. 2018; Ali et al. 2019; Astuti et al. 2019; Câmara et al. 2019; de Araujo et al. 2019; Ghazala et al. 2019; Maia et al. 2019). Biosurfactants can recover around 10-85\% of oil from sand pack columns or core floods. For example, the biosurfactant produced by Fusarium sp. BS- 8 recovered $45 \%$ of the oil in a sand pack column (Qazi et al. 2013). There are several advantages for oil recovery using biosurfactants, such as the use of cheap agro-industrial waste, faster production, and high success rates (Nayak et al. 2009; de Araujo et al. 2019). However, there are some major challenges associated with biosurfactant-mediated oil recovery including the cost effectiveness of using chemical surfactants compared with biosurfactants, capital expenditure to buy the industrial bioreactors needed for scale-up, and, similarly to chemical surfactants, biosurfactant have issues with adsorption to rock (Geetha et al. 2018).

\section{Conclusion}

In the present study, we demonstrated that Trichoderma sp. MK116452 is a potential source of biosurfactant for oil recovery. The biosurfactant produced by this strain had the ability to recover oil using the sand pack column method at similar rates to a synthetic surfactant. This biosurfactant is a glycolipid and has low toxicity compared with that of chemical surfactants, making it preferable for use in environmental applications.

Abbreviation
\begin{tabular}{|c|l|}
\hline amu & Atomic mass unit \\
\hline Bbl & Barrel \\
\hline${ }^{\circ} \mathrm{C}$ & Degree Celsius \\
\hline EOR & Enhanced oil recovery \\
\hline E24 & Emulsion index \\
\hline GI & Germination index \\
\hline
\end{tabular}




\begin{tabular}{|c|l|}
\hline $\mathrm{g}$ & Gram \\
\hline $\mathrm{g} / \mathrm{L}$ & Gram per litre \\
\hline $\mathrm{h}$ & Hour \\
\hline$\mu \mathrm{L}$ & Microlitre \\
\hline $\mathrm{mL}$ & Millilitre \\
\hline $\mathrm{min}$ & Minute \\
\hline $\mathrm{NCBI}$ & National Centre of Biotechnology \\
\hline $\mathrm{NMR}$ & Nuclear magnetic resonance \\
\hline$\%$ & Percentage \\
\hline $\mathrm{rpm}$ & Revolutions per minute \\
\hline
\end{tabular}

\section{Ethics approval and consent to participate}

Not applicable

\section{Consent for publications}

All the authors have given their consents for this paper to be published.

\section{Availability of data and materials}

The data that supporting the results in this paper could be found in Scopus and Science directs.

\section{Competing interests}

The authors declare that they have no competing interests.

\section{Acknowledgements}

The authors gratefully acknowledge the support and facilities provided by Universiti Brunei Darussalam.

\section{Author's contributions}

All authors have contributed fairly in this paper. Bazilah Matussin designed and performed the experiments; Bazilah Matussin, Pooja Shivanand and Lim Lee Hoon analysed the data; Pooja Shivanand and Lim Lee Hoon contributed materials; Bazilah Matussin, Pooja Shivanand and Lim Lee Hoon wrote the paper. 


\section{Funding}

This work was supported by the Universiti Brunei Darussalam [grant no. UBD/OAVCRI/CRGWG(010)/170501].

\section{References}

Ali N, Wang F, Xu B, et al (2019) Production and Application of Biosurfactant Produced by Bacillus Licheniformis Ali5 in Enhanced Oil Recovery and Motor Oil Removal from Contaminated Sand. Molecules 24:1-19. https://doi.org/10.3390/molecules24244448

Ashish, Debnath (Das) M (2018) Application of biosurfactant produced by an adaptive strain of C. tropicalis MTCC230 in microbial enhanced oil recovery (MEOR) and removal of motor oil from contaminated sand and water. J Pet Sci Eng 170:40-48. https://doi.org/10.1016/j.petrol.2018.06.034

Astuti DI, Purwasena IA, Putri RE, et al (2019) Screening and characterization of biosurfactant produced by Pseudoxanthomonas sp. G3 and its applicability for enhanced oil recovery. J Pet Explor Prod Technol 9:2279-2289. https://doi.org/10.1007/s13202-019-0619-8

Bansal S, Singh J, Kumari U, et al (2019) Development of biosurfactant-based graphene quantum dot conjugate as a novel and fluorescent theranostic tool for cancer. Int $\mathbf{J}$ Nanomedicine 14:809-818. https://doi.org/10.2147/IJN.S188552

Bhawsar NA, Singh M (2016) GC-MS profile of Biosurfactant producing and Hydrocarbon degrading $P$. aeruginosa NGB4 in liquid culture system. J Pharm Res 10:726-729

Bodour AA, Miller-Maier RM (1998) Application of a modified drop-collapse technique for surfactant quantitation and screening of biosurfactant-producing microorganisms. J Microbiol Methods 32:273-280. https://doi.org/10.1016/S0167-7012(98)00031-1

Câmara JMDA, Sousa MASB, Barros Neto EL, Oliveira MCA (2019) Application of rhamnolipid biosurfactant produced by Pseudomonas aeruginosa in microbial-enhanced oil recovery (MEOR). J Pet Explor Prod Technol 0:0. https://doi.org/10.1007/s13202-019-0633-X

Cortés-Sánchez A de J, Hernández-Sánchez H, Jaramillo-Flores ME (2013) Biological activity of 
glycolipids produced by microorganisms: New trends and possible therapeutic alternatives. Microbiol Res 168:22-32. https://doi.org/10.1016/j.micres.2012.07.002

de Araujo LLGC, Sodré LGP, Brasil LR, et al (2019) Microbial enhanced oil recovery using a biosurfactant produced by Bacillus safensis isolated from mangrove microbiota - Part I biosurfactant characterization and oil displacement test. J Pet Sci Eng 180:950-957. https://doi.org/10.1016/j.petrol.2019.06.031

Dhiman R, Meena KR, Sharma A, Kanwar SS (2016) Biosurfactants and their Screening Methods. $5: 39-43$

Geetha SJ, Banat IM, Joshi SJ (2018) Biosurfactants: Production and potential applications in microbial enhanced oil recovery (MEOR). Biocatal Agric Biotechnol 14:23-32. https://doi.org/10.1016/j.bcab.2018.01.010

Ghazala I, Bouallegue A, Haddar A, Ellouz-Chaabouni S (2019) Characterization and production optimization of biosurfactants by Bacillus mojavensis I4 with biotechnological potential for microbial enhanced oil recovery. Biodegradation 30:235-245. https://doi.org/10.1007/s10532-018-9844-y

High LS, Ayaz M, Junaid M, et al (2016) Molecularly Characterized Solvent Extracts and Saponins from Shrimp, and Fibroblast NIH / 3T3 Cell Line Cytotoxicity. 7:1-13. https://doi.org/10.3389/fphar.2016.00074

Ibrahim ML, Ijah UJJ, Manga SB, et al (2013) Production and partial characterization of biosurfactant produced by crude oil degrading bacteria. Int Biodeterior Biodegrad 81:28-34. https://doi.org/10.1016/j.ibiod.2012.11.012

Kanna R (2017) Biological surfactant production by Pseudomonas aeruginosa atcc 9027 and probable application in microbial enhanced oil recovery (MEOR). Int J Civ Eng Technol 8:619-626

Liu J, Chen Y, Xu R, Jia Y (2013) Screening and Evaluation of Biosurfactant-Producing Strains Isolated from Oilfield Wastewater. Indian J Microbiol 53:168-174. https://doi.org/10.1007/s12088-013-0379-y 
Luna JM, Filho ASS, Rufino RD, Sarubbo LA (2016) Production of Biosurfactant from Candida bombicola URM 3718 for Environmental Applications. 49:583-588. https://doi.org/10.3303/CET1649098

Maheswari NUMA, Parveen LF (2012) Comparative Study Of Biosurfactant By Using Bacillus Licheniformis And Trichoderma Viride From Paper Waste Contaminated Soil. 10:1687-1697

Maia M, Capão A, Procópio L (2019) Biosurfactant produced by oil-degrading Pseudomonas putida AM-b1 strain with potential for microbial enhanced oil recovery. Bioremediat $\mathbf{J}$ 23:302-310. https://doi.org/10.1080/10889868.2019.1669527

Morikawa M, Daido H, Takao T, et al (1993) A new lipopeptide biosurfactant produced by $\begin{array}{llllll}\text { Arthrobacter sp. } & \text { strain } & \text { MIS38. J } & \text { B }\end{array}$ https://doi.org/10.1128/jb.175.20.6459-6466.1993

Nayak AS, Vijaykumar MH, Karegoudar TB (2009) Characterization of biosurfactant produced by Pseudoxanthomonas sp. PNK-04 and its application in bioremediation. Int Biodeterior Biodegrad 63:73-79. https://doi.org/10.1016/j.ibiod.2008.07.003

Ndlovu T, Rautenbach PM (2017) Bioprospecting for Novel Biosurfactants and Biosurfactant Producing Bacteria in Wastewater

Parthipan P, Preetham E, Machuca LL, et al (2017a) Biosurfactant and degradative enzymes mediated crude oil degradation by bacterium Bacillus subtilis A1. Front Microbiol 8:1-14. https://doi.org/10.3389/fmicb.2017.00193

Parthipan P, Preetham E, Machuca LL, et al (2017b) Biosurfactant and Degradative Enzymes Mediated Crude Oil Degradation by Bacterium Bacillus subtilis A1. Front Microbiol 8:1-14. https://doi.org/10.3389/fmicb.2017.00193

Patowary K, Patowary R, Kalita MC, Deka S (2017) Characterization of biosurfactant produced during degradation of hydrocarbons using crude oil as sole source of carbon. Front Microbiol 8:1-14. https://doi.org/10.3389/fmicb.2017.00279

Peng F, Wang Y, Sun F, et al (2008) A novel lipopeptide produced by a Pacific Ocean deep-sea 
bacterium, Rhodococcus sp. TW53. J Appl Microbiol 105:698-705. https://doi.org/10.1111/j.1365-2672.2008.03816.x

Qazi M, Subhan M, Fatima N (2013) Role of biosurfactant produced by Fusarium sp. BS-8 in enhanced oil recovery (EOR) through sand pack column. Int J Biosci Biochem 3, https://doi.org/10.7763/IJBBB.2013.V3.284

Raza ZA, Khan MS, Khalid ZM (2007) Physicochemical and surface-active properties of biosurfactant produced using molasses by a Pseudomonas aeruginosa mutant. J Environ Sci Heal - Part A Toxic/Hazardous Subst Environ Eng 42:73-80. https://doi.org/10.1080/10934520601015784

Ron EZ, Rosenberg E (2002) Biosurfactants and oil bioremediation. Curr Opin Biotechnol 13:249-252. https://doi.org/10.1016/S0958-1669(02)00316-6

Rufino RD, de Luna JM, de Campos Takaki GM, Sarubbo LA (2014) Characterization and properties of the biosurfactant produced by Candida lipolytica UCP 0988. Electron J Biotechnol 17:34-38. https://doi.org/10.1016/j.ejbt.2013.12.006

Santhappan R, Pandian MR (2017) Biodegradation Characterization of Novel Biosurfactants Produced by the Strain Fusarium oxysporum. J Bioremediation Biodegrad 8:6-11. https://doi.org/10.4172/2155-6199.1000416

Santos APP, Silva MDS, Costa EVL, et al (2018) Production and characterization of a biosurfactant produced by Streptomyces sp. DPUA 1559 isolated from lichens of the Amazon region. Brazilian J Med Biol Res 51:1-10. https://doi.org/10.1590/1414-431x20176657

Santos DKF, Meira HM, Rufino RD, et al (2017) Biosurfactant production from Candida lipolytica in bioreactor and evaluation of its toxicity for application as a bioremediation agent. Process Biochem 54:20-27. https://doi.org/10.1016/j.procbio.2016.12.020

Satpute SK, Banpurkar AG, Dhakephalkar PK, et al (2010) Methods for investigating biosurfactants and bioemulsifiers: A review. Crit Rev Biotechnol 30:127-144. https://doi.org/10.3109/07388550903427280 
Sharma D, Saharan BS, Chauhan N, et al (2014) Production and Structural Characterization of Lactobacillus helveticus Derived Biosurfactant. 2014:25-31. https://doi.org/10.1155/2014/493548

Sharma D, Saharan BS, Chauhan N, et al (2015) Isolation and functional characterization of novel biosurfactant produced by Enterococcus faecium. 1-14

Sharma R, Singh J, Verma N (2018) Production, characterization and environmental applications of biosurfactants from Bacillus amyloliquefaciens and Bacillus subtilis. Biocatal Agric Biotechnol 16:132-139. https://doi.org/10.1016/j.bcab.2018.07.028

Sobrinho HB de S, de Luna JM, Rufino RD, et al (2013) Assessment of toxicity of a biosurfactant from Candida sphaerica UCP 0995 cultivated with industrial residues in a bioreactor. Electron J Biotechnol 16:. https://doi.org/10.2225/vol16-issue4-fulltext-4

Solis PN, Wright CW, Gupta MP (2006) A Microwell Cytotoxicity Assay using Artemia Salina ( Brine Shrimp ). https://doi.org/10.1055/s-2006-959661

Thavasi R, Sharma S, Jayalakshmi S (2013) Evaluation of Screening Methods for the Isolation of Biosurfactant Producing Marine Bacteria. J Pet Environ Biotechnol 04: https://doi.org/10.4172/2157-7463.S1-001

Varjani SJ, Upasani VN (2017) Critical review on biosurfactant analysis, purification and characterization using rhamnolipid as a model biosurfactant. Bioresour Technol 232:389397. https://doi.org/10.1016/j.biortech.2017.02.047

Walter V, Syldatk C, Hausmann R (2010) Screening Concepts for the Isolation of Biosurfactant Producing Microorganisms. In: Advances in Experimental Medicine and Biology. pp 1-13

Zhang X, Xu D, Zhu C, et al (2012) Isolation and identification of biosurfactant producing and crude oil degrading Pseudomonas aeruginosa strains. Chem Eng J 209:138-146. https://doi.org/10.1016/j.cej.2012.07.110 


\section{Figures}

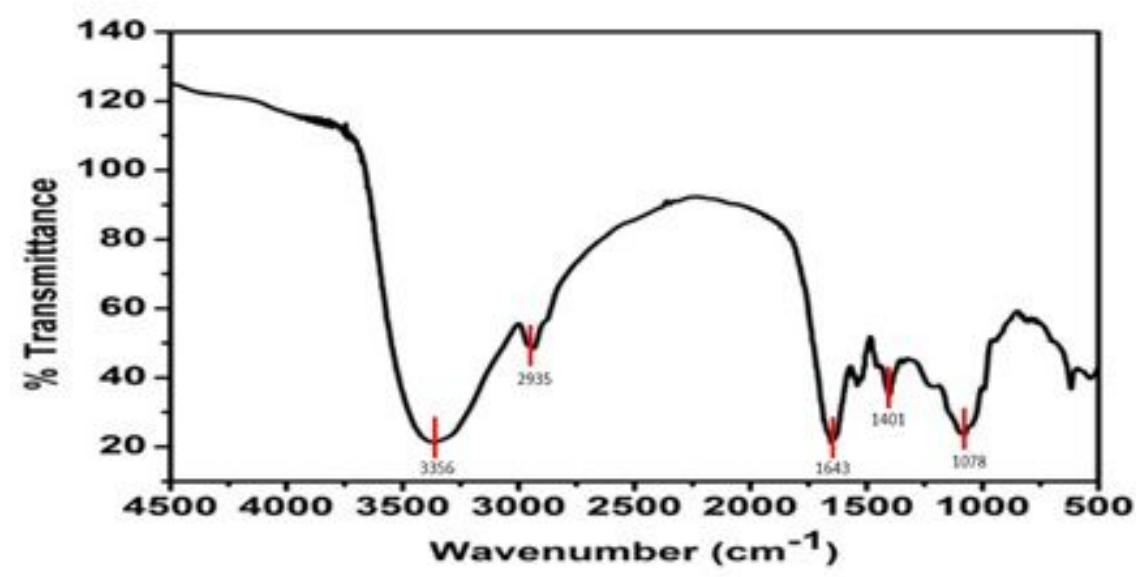

Figure 1

Fourier-transform infrared (FTIR) spectrum for a biosurfactant from Trichoderma sp. MK116452

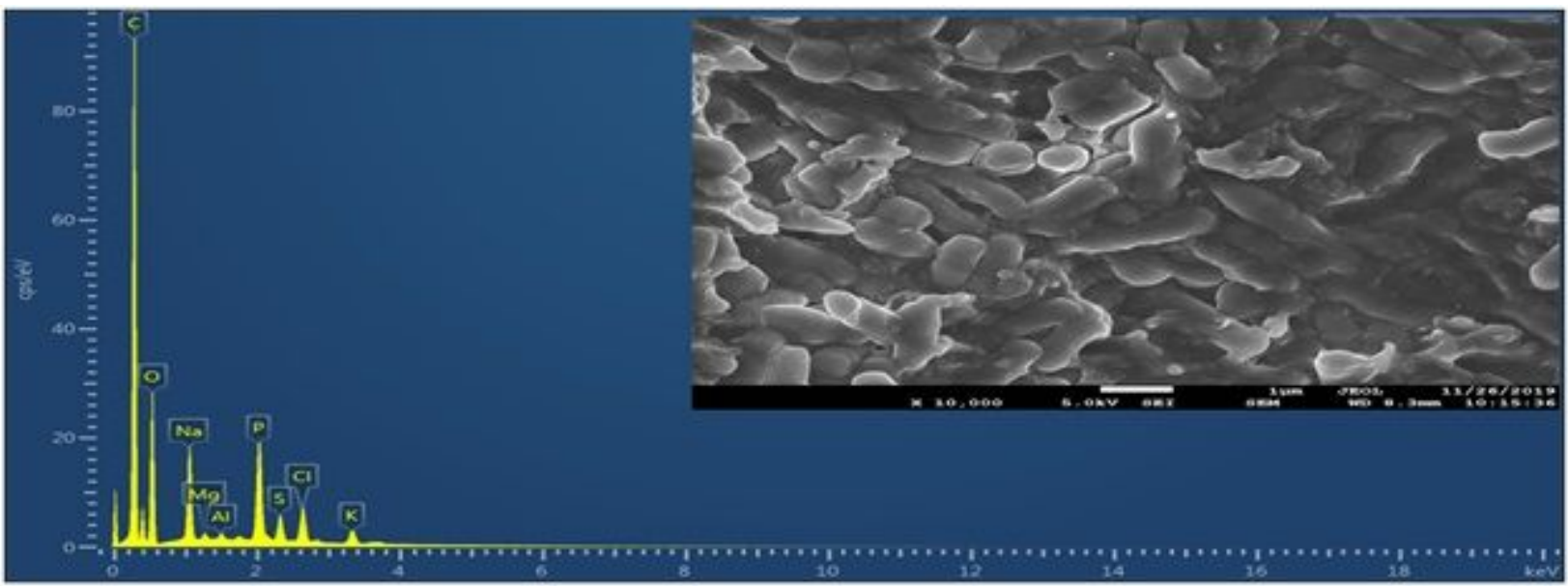

Figure 2

SEM EDS images for biosurfactant produced by Trichoderma sp. MK116452 